\title{
To what extent do fiscal regimes equalize opportunities for income acquisition among citizens?
}

\author{
John E. Roemer ${ }^{a}, *$, Rolf Aaberge ${ }^{\mathrm{b}}, \mathrm{Ugo}_{\text {Colombino }}{ }^{\mathrm{c}}$, Johan Fritzell ${ }^{\mathrm{d}}$, \\ Stephen P. Jenkins ${ }^{\mathrm{e}}$, Arnaud Lefranc ${ }^{\mathrm{f}}$, Ive Marx ${ }^{\mathrm{g}}$, Marianne Page ${ }^{\mathrm{h}}$, \\ Evert Pommer ${ }^{\mathrm{i}}$, Javier Ruiz-Castillo ${ }^{\mathrm{j}}$, Maria Jesus San Segundo ${ }^{\mathrm{j}}$, \\ Torben Tranaes ${ }^{\mathrm{k}}$, Alain Trannoy ${ }^{\mathrm{f}}$, Gert G. Wagner ${ }^{1}$, Ignacio Zubiri ${ }^{\mathrm{m}}$ \\ ${ }^{a}$ Department of Political Science, Yale University, PO Box 208301, New Haven, CT 06520, USA \\ ${ }^{\mathrm{b}}$ Statistics Norway, Oslo, Norway \\ ${ }^{\mathrm{c}}$ University of Turin, Turin, Italy \\ ${ }^{\mathrm{d}}$ Stockholm University, Stockholm, Sweden \\ ${ }^{\mathrm{e}}$ University of Essex, Essex, UK \\ ${ }^{\mathrm{f}}$ University of Cergy-Pontoise, Cergy-Pontoise, France \\ ${ }^{\mathrm{g}}$ University of Antwerp, Antwerp, Belgium \\ ${ }^{\mathrm{h}}$ University of California, Davis, CA, USA \\ i Dutch Social and Cultural Planning Office, The Hague, The Netherlands \\ ${ }^{\mathrm{j}}$ University Carlos III, Madrid, Spain \\ ${ }^{\mathrm{k}}$ Danish National Institute of Social Research, Copenhagen, Denmark \\ ${ }^{1}$ German Institute for Economic Research (DIW Berlin), Berlin, Germany \\ ${ }^{\mathrm{m}}$ University of the Basque Country, Bilbao, Spain
}

Received 26 April 2000; received in revised form 13 February 2001; accepted 7 June 2001

\begin{abstract}
This paper employs the theory of equality of opportunity, described in Roemer's book (Equality of Opportunity, Harvard University Press, 1998), to compute the extent to which tax-and-transfer regimes in 11 countries equalize opportunities among citizens for income acquisition. Roughly speaking, equality of opportunity for incomes has been achieved in a country when it is the case that the distributions of post-fisc income are the same for different types of citizen, where a citizen's type is defined by the socio-economic status of his parents. Intuitively, a country will have equalized opportunity if the chances of earning high (or low) income are equal for citizens from all family backgrounds. Of course, pre-fisc income distributions, by type, will not be identical, as long as the educational system does
\end{abstract}

\footnotetext{
*Corresponding author. Tel.: +1-203-432-5249; fax: +1-203-432-6196.

E-mail address: john.roemer@yale.edu (J.E. Roemer).
} 
not entirely make up for the disadvantage that children, who come from poor families face, but the tax-and-transfer system can play a role in rectifying that inequality. We include, in our computation, two numbers that summarize the extent to which each country's current fiscal regime achieves equalization of opportunities for income, and the deadweight loss that would be incurred by moving to the regime that does.

(C) 2001 Elsevier Science B.V. All rights reserved.

Keywords: Fiscal regimes; Equal opportunities; Income acquisition

JEL classification: D63; H00

\section{Introduction}

In this study we ask: To what extent do the tax-and-transfer regimes in 11 advanced countries equalize opportunities, among their citizens, for income acquisition? We intend to subject an idea in contemporary political philosophy to economic analysis, and thereby to evaluate the performance of fiscal systems with respect to one arguably important ethical measure.

Many scholars have pondered, over the years, the justness or fairness of taxation. A well-known tradition views taxation as an instrument to maximize average utility in a society — this is the 'utilitarian' objective. A more recent tradition captures social welfare with a Rawlsian objective function: here, just taxation is that which maximizes the welfare of the least well-off individual. More recently, political philosophers of an egalitarian stripe have criticized the Rawlsian view as ignoring the issue of personal responsibility. These writers (Dworkin, 1981a,b; Arneson, 1989, 1990; Cohen, 1989; Roemer, 1993, 1998), to name several, have argued that equality of outcomes, which the Rawlsian objective considers the ideal, is not ethically desirable, for it fails to recognize that differences in outcomes due to differential efforts or ambitions by individuals are ethically acceptable. ${ }^{1}$ What these writers propose is that egalitarians should seek not to equalize outcomes, but only seek to equalize that part of outcomes which are due, in Dworkin's phrase, to 'brute luck,' which, roughly speaking, means to factors for which the individual in question should not be held responsible, because they were beyond his control. In the terminology we adopt below, it is desirable to equalize outcomes in so far as they are different because of the

\footnotetext{
${ }^{1}$ We are here being, perhaps importantly, unfair to Rawls. For Rawls advocated the equality of primary goods, not outcomes. Nevertheless, in economic applications, most researchers have substituted 'utility' or 'income' for Rawls's 'primary goods.' In the former case, this move can be made consistent with Rawls by arguing that the utility function adopted by the researcher is really an index of primary goods (say, income and leisure).
} 
influence of differential circumstances, but not in so far as they are due to differential effort. We call these theories, generically, equal-opportunity theories.

Utilitarianism is a welfarist theory: to order two social alternatives (say, the outcomes citizens enjoy under two different tax regimes), the utilitarian requires knowledge only of the utilities of individuals under the two social alternatives. Similarly, the Rawlsian objective, as it is commonly used by economists, is welfarist - one need only know the welfare (or some other outcome) of the worst-off individual under two alternatives to render a judgment of which alternative is better. In contrast, equal-opportunity theories are non-welfarist: for to render a judgment about which social alternative is better, one need know the efforts expended by the individuals in the two alternatives, not simply the outcomes they enjoy under them.

Most citizens of western democracies are not welfarist: for example, they generally support transfers to poor compatriots if the latter are poor due to no fault of their own; many fewer, however, support generous transfers if the recipients' impecunious position is due to irresponsible behavior - in our terminology, to low effort. Thus, not only the outcome, but how it came about, matters. If we are correct in conjecturing that most people in many countries do have this nonwelfarist ethic, then it is unlikely that they will assent to the recommendation of a welfarist optimal taxation exercise. In contrast, we think that the theory of equal opportunity that we employ here is closer to the ethics of many, if not most, citizens of western democracies, and therefore the non-welfarist optimal taxation exercise of this article is more in tune with popular sentiments. We do not exclude the possibility, however, that in some of the more egalitarian European countries, where there is an explicit political focus on equality of outcome, citizens may endorse the welfarist view.

We formalize the posing of our title's question with Roemer's (1998) theory of equality of opportunity. The vocabulary of that theory consists principally in five words: objective, circumstances, type, effort, and instrument. The objective is the condition of individuals whose acquisition we desire to equalize opportunities for, in the present case, income acquisition. Circumstances are attributes of the environment of the individual (which may be social, genetic, or biological) that influence the extent to which he will achieve the objective, and which are 'beyond his control,' or, more generally, attributes for which society deems him not to be responsible. Effort is that constellation of behaviors, on the individual's part, which together with circumstances will determine the value of the objective for him. (Where does luck belong? Unfortunately, it will appear as effort, because we will measure effort as a residual after circumstances are accounted for.) We use the instrument - often the provision of resources - to compensate individuals with disadvantageous circumstances, in order to improve their chances of realizing an acceptably high value of the objective. The purpose of equal-opportunity policy is to 'level the playing field' among individuals, who compete for an objective, in the following sense: after that leveling, a person's acquisition of the objective should 
be a function only of his effort and not of his circumstances. Thus, the instrument is used to compensate those with poor circumstances so that, in expectation, after the compensation, a person's achievement of the objective will be sensitive only to his effort. ${ }^{2}$ Finally, a type is the set of individuals all of whom have the same circumstances. Circumstances partition the set of individuals into types.

It is, of course, a deep philosophical question, with psychological and neurophysiological components, to determine exactly what constitutes the complete set of circumstances for any given social problem. In practice, we choose some circumstances for the purpose of the computation, and define the partition of types with respect to those. We then arbitrarily attribute the variation in the acquisition of the objective among those within a type entirely to differential effort. Thus, in applying the theory, we always view effort as the residual that explains differential outcomes (in values of the objective), once circumstances have been delineated. (Thus, the effects of luck, as we said earlier, will be accounted for as 'effort.') Because of this procedure, the equal-opportunity policy we compute probably undercompensates disadvantaged individuals, for some of what we will call 'effort' should (if we had the data and knowledge) be ascribed to a more inclusive set of circumstances.

To summarize the ethic behind equality of opportunity (EOp): inequality of outcome due to the differential application of effort is morally all right, but if it is due to differential circumstances, then it is not morally all right, and is compensable by society. The EOp view holds a person responsible for his effort, but not for his circumstances.

Let us now formalize this approach (here we review, very briefly, the presentation of Roemer, 1998). Let the circumstances and objective be given, let the set of types defined by these circumstances be $T$, with generic element $t \in T$. Suppose the value of the instrument or policy (say, some resource allocation or tax policy) is $\varphi$, chosen from some set of feasible policies, $\Phi$. Then there will ensue some distribution of the value of the objective within each type. Think of there being a continuum of individuals of each type. Let $v^{t}(\pi, \varphi)$ be the value of the objective $^{3}$ at the $\pi$ th quantile (where $\pi \in[0,1]$ ) of the distribution of the objective in type $t$, at the policy $\varphi$. Our desire is to choose that value of the instrument $\varphi$ which equalizes the value of the objective across types at any given degree of effort.

Our next move is to identify all those who sit at the $\pi$ th quantiles of their type

\footnotetext{
${ }^{2}$ Thus, the troughs in the playing field are the disadvantages some face due to unfortunate circumstances.

${ }^{3}$ The approach is somewhat unconventional in eclipsing the analysis of individual choice. We do not represent the utility functions of individuals within a type that lead them to choose different outcomes when facing a policy. Those may be introduced (see Roemer, 1998). Despite the fact that we do not explicitly model that type-heterogeneous choice behavior, it is important to emphasize that the different outcomes of individuals within a type are due to choices for which we hold the individual responsible.
} 
distributions of the objective as having expended effort in the same degree, for any fixed $\pi$.

Suppose we could measure effort directly, and observe an effort distribution in each type. Those distributions would be characteristics of the types. Some types would have 'better' distributions of effort than others, and this must be due to their type, that is, their circumstances. Since our aim is to not hold persons responsible for characteristics of their type, we should not hold them responsible for characteristics of their effort which are due to their being in a disadvantaged type. We require an inter-type-comparable effort measure that factors out the goodness or badness of the effort distribution per se. This suggests that we measure a person's effort by the quantile at which he or she sits on the effort-distribution of his or her type, for the quantile measure ranks a person's effort by comparing him only to others of his type. Since that measure is relative, rather than absolute, it is as well a compelling inter-type comparable measure of effort.

We thus declare: two individuals in different types have expended the same degree of effort if they sit at the same rank of the effort distribution of their types. We next note that, if we either ignore luck, or assume that it averages out, outcomes are a function of circumstances, effort, and policy, a function which is monotone increasing in effort (ex hypothesis). We now consider policies that treat all members of a given type identically. Then two individuals in different types who are at the same quantiles of their respective effort distributions, at a given policy, also sit at the same quantile of the outcome distribution of their types. This follows from the monotonicity property just mentioned. It is essential to underscore that, for this monotonicity argument to hold, all members of a given type must face the same policy.

Thus, our goal becomes: To choose that policy $\varphi$ which makes it the case that the type distributions of the objective are as close as possible to being 'equal.' More precisely, we do not want to 'equalize' these distributions, but to 'maximin' them: 'equalizing' could be achieved by driving the objective value to zero for everyone. The formalization of the objective proposed in Roemer (1998) is to 'maximin' these distributions in the precise sense of solving this program:

$$
\underset{\varphi \in \Phi}{\operatorname{Max}} \int_{0}^{1} \operatorname{Min}_{t} v^{t}(\pi, \varphi) \mathrm{d} \pi .
$$

Program (1.1) chooses that policy that maximizes the area under the lower envelope of the functions $\left\{v^{t}(\cdot, \varphi)\right\}$.

Program (1.1) is motivated as follows. Suppose we fix, for the moment, a

\footnotetext{
${ }^{4}$ The reader should recall that effort here is not merely 'labor' or 'intensity of labor', but rather a multi-dimensional set of behaviors, including the acquisition of skill, intensity of job search, and so on, which engender the final outcome of income acquisition.

${ }^{5}$ This means that all members of a given type face the same policy.
} 
particular quantile of effort, $\pi$. The policy which maximins the value of the objective, across types, for all those who sit at the $\pi$ th quantile of their effort distributions is

$$
\varphi^{\pi}=\underset{\varphi \in \Phi}{\operatorname{ArgMax}} \operatorname{Min}_{t \in T} v^{t}(\pi, \varphi)
$$

Here we have used the fact, deduced above, that those at a given quantile $\pi$ of their type distributions of the objective have expended the same degree of effort, which we may also index ordinally as the $\pi$ th degree. In general, there is a continuum of such policies, $\left\{\varphi^{\pi}\right\}$, one for each $\pi$. The first-best solution to our problem is achievable only when all these policies are identical. More generally, when this is not so, we require some second-best compromise. Program (1.1) uses an additive social objective function in which the objective function of the citizens in each quantile $\pi$, namely $\operatorname{Min}_{t \in T} v^{t}(\pi, \varphi)$, receives the same weight. ${ }^{6}$

Social-choice enthusiasts will note that the program (1.1) is 'Rawlsian' with respect to outcomes attributable to differential circumstances, but 'utilitarian' with respect to outcomes attributable to differential effort. It puts great value on reducing differences due to differential circumstances, but no particular value on reducing differences due to differential effort.

\section{Income taxation and transfers and the characterization of EOp policy}

The income tax regime of a country, by which we mean the set of income taxes and cash transfers from the government, is a device both for raising revenue for the government budget, and for redistributing income. We can ask: to what extent does the income tax regime of a country equalize opportunities among its citizens for the acquisition of income? We shall render this question precise as follows. We shall first partition the set of citizens into several (indeed, three) types, based on a single circumstance: the level of education of their parents. We shall characterize a policy as a mapping from pre-fisc to post-fisc income. We shall restrict ourselves to affine policies, and represent the generic policy by an ordered pair $(a, c)$ : if $x$ is pre-fisc income, then $(1-a) x+c$ is post-fisc income under policy $(a, c)$. We shall

\footnotetext{
${ }^{6}$ Other formulations are possible. For instance, Van de Gaer (1993) proposes to commute the 'min' operator and the integral sign in (1.1):

$$
\underset{\varphi \in \Phi}{\operatorname{Max}} \operatorname{Min}_{t} \int_{0}^{1} v^{t}(\pi, \varphi) \mathrm{d} \pi
$$

In fact, in the application of this article, both formulae lead to the same result.

${ }^{7}$ Pre-fisc income is income from the 'market' (see later for details). Post-fisc income is pre-fisc income plus cash transfer payments from the government minus income tax payments.
} 
define a set of feasible policies, $\Phi$, for a country. We shall define, and indeed compute, $v^{t}(\pi ; a, c)$ to be the post-fisc income of citizens at the $\pi$ th quantile of the post-fisc income distribution in type $t$ (for $t=1,2,3$ ) at the policy $(a, c)$; we shall then compute the solution to program (1.1). This will be the policy that equalizes opportunities for income. We shall finally compare this policy with the actual tax-and-transfer policy in the country.

In words, we will have computed the fiscal policy that makes it the case that the distributions of post-fisc income across the three types are 'as close as possible to being equal' in the sense of our objective (1.1). Program (1.1) makes no effort per se to shrink the variation in incomes across effort levels, but only across types, which reflects the view that differences in outcomes due to differential effort are ethically acceptable.

Our computation in fact corresponds to a familiar conception of equality of opportunity, one based on mobility matrices. Think of a mobility matrix whose rows are labeled 'socio-economic status of the family a person comes from' (here captured as his parents' level of education), and whose columns are various income levels. Element $i j$ of the matrix is the fraction of persons from families whose parents were of socio-economic status $i$ and who end up earning income level $j$. Equality of opportunity holds if the rows of this matrix are identical: that is the distributions of income should be the same for types who come from different social backgrounds. Our computation will find the tax policy $(a, c)$ that makes the rows of this matrix 'as close as possible to being equal (in the maximin sense)'.

Let us continue interpreting (1.1). Let $G_{\varphi}^{t}(y)$ be the (cumulative) distribution function of post-fisc income, $y$, in type $t$, at policy $\varphi$. Then by definition:

$$
\pi=G_{\varphi}^{t}\left(v^{t}(\pi, \varphi)\right)
$$

Now $G_{\varphi}^{t}$, being a distribution function, is monotonic, and possesses an inverse, which we denote $\left(G_{\varphi}^{t}\right)^{-1}$. Applying this inverse to (2.1), we have:

$$
\left(G_{\varphi}^{t}\right)^{-1}(\pi)=v^{t}(\pi, \varphi)
$$

Substituting from (2.2) into (1.1), our objective becomes

$$
\operatorname{Max}_{\varphi \in \Phi} \int_{0}^{1} \operatorname{Min}_{t}\left(G_{\varphi}^{t}\right)^{-1}(\pi) \mathrm{d} \pi .
$$

There is a simple geometric interpretation of (2.3). For simplicity let there be two types, and suppose that their two distribution functions for a particular $\varphi, G_{\varphi}^{1}$ and $G_{\varphi}^{2}$, are as pictured in Fig. 1. Then the integral in (2.3) is simply the area bounded by the vertical axis, the horizontal axis, the line at the ordinate value one, and the left-hand envelope of the graphs of $G_{\varphi}^{1}$ and $G_{\varphi}^{2}$.

In Fig. 1, we have drawn the graphs of these two distribution functions as 


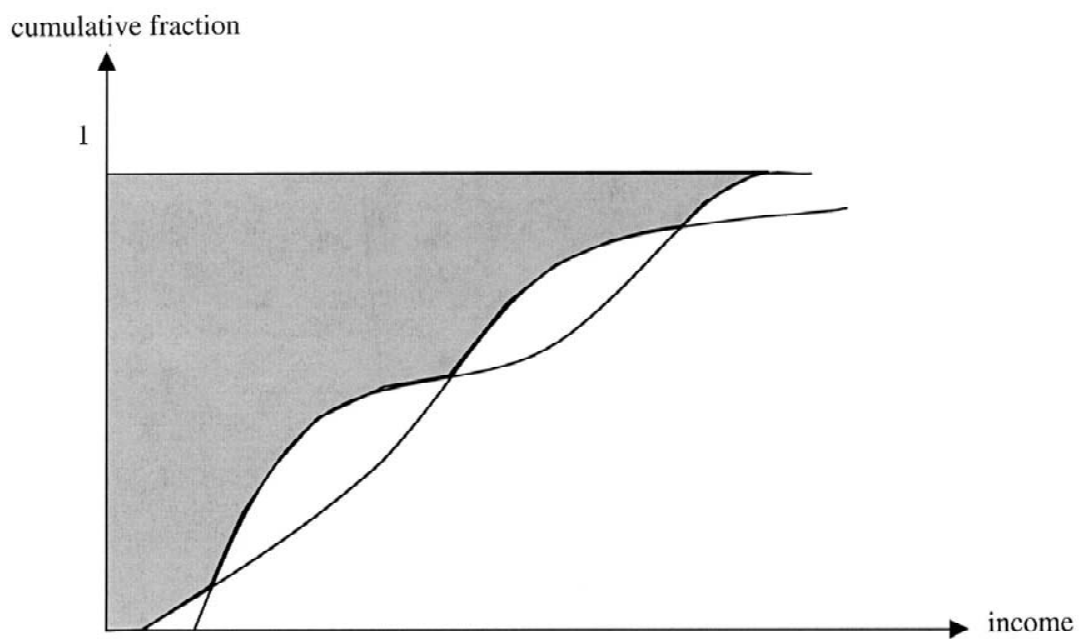

Fig. 1. The objective of program (2.3).

intersecting in several places, for purposes of generality. But in our particular application, the distribution functions of pre-fisc income, for the various types, will (usually) not cross, and because the tax regime $(a, c)$ is monotonic $(a<1)$, the post-fisc income distributions of different types will also not cross. Therefore, in our application, (2.3) says to choose $\varphi$ to maximize the area to the left of the post-fisc distribution function of the most disadvantaged type, bounded by the axes and line $y=1$. But it is well-known (and easy to see) that this is just the average post-fisc income of the most disadvantaged type. Hence our equal-opportunity program reduces, in this case, to a simple prescription:

Find that policy that maximizes the average post-fisc income of the most disadvantaged type.

We must emphasize that this simple prescription, which does not generally hold in equal-opportunity calculations, is due to a particular feature of the present set-up: that the policies we consider will not change the ranks of any two individuals in moving from the pre-fisc to the post-fisc income distribution. This would not be the case if, for instance, we allowed policies which taxed different types at different rates. Such policies would, in general, cause the post-fisc

\footnotetext{
${ }^{8}$ This prescription contrasts with the Rawlsian difference principle, which would be to maximize the post-fisc income of the worst-off individual. Rawls, thus interpreted, would not hold individuals responsible for their effort levels, while the EOp view does. It must be said, however, that at times, Rawls says that his prescription is to maximize the bundle of primary goods going to the worst-off class of individuals.
} 
distributions of income of different types to cross, and the 'simple prescription', described above, would be an incorrect characterization of the equal-opportunity policy.

We now proceed to the optimal-tax calculation. (We refer to a particular country throughout this explanation.) We shall observe, for each of the countries in our sample, the pre-fisc and post-fisc distributions of income, in aggregate, and by type. We shall compute the best-fitting affine policy which explains the aggregate data, which we denote $(\hat{a}, \hat{c})$. As we shall observe, these affine tax policies fit extremely well: despite statutory progressivity in marginal tax rates, the observed tax-and-transfer policy is, for all practical purposes, affine, in almost all countries of our study. 'We now attribute a uniform, quasi-linear utility function

$$
u(y, L)=y-\alpha L^{1+1 / \eta}
$$

to each citizen in the country, where $y$ is post-fisc income and $L$ is labor. Recall that, for this utility function, $\eta$ is the elasticity of labor supply with respect to the wage. For a citizen who earns a wage of $w$, and faces a tax policy $(a, c)$, the optimal labor supply is

$$
L(w ; a, c)=\left[\frac{(1-a) w}{\hat{\alpha}}\right]^{\eta},
$$

where $\hat{\alpha} \equiv \alpha(1+1 / \eta)$, and hence the individual's pre-fisc income is

$$
x(w ; a, c)=\left[\frac{1-a}{\hat{\alpha}}\right]^{\eta} w^{1+\eta} .
$$

If $g$ is the value of government services (non-transfer payments) per capita, and if $\mathbf{F}$ is the probability measure of wages, then it follows that the government budget constraint is:

$$
a \int\left(\frac{1-a}{\hat{\alpha}}\right)^{\eta} w^{1+\eta} \mathrm{d} \mathbf{F}(w)=c+g .
$$

Letting $g$ be given, we may express $c$ as a function of $a$ :

$$
c=a\left(\frac{1-a}{\hat{\alpha}}\right)^{\eta} B-g
$$

where $B=\int w^{1+\eta} \mathrm{d} \mathbf{F}$. Thus, for $g$ and $\mathbf{F}$ given, our policy space is now unidimensional. To be precise, we let the set of policies $\Phi$ for a country be the set

\footnotetext{
${ }^{9}$ In an earlier paper (Page and Roemer, in press), we worked with a larger class of tax policies, the set of quadratic income taxes, in the analysis of one country (the United States). This complicates the optimal-tax analysis substantially, without changing the results significantly. Because of the ubiquity of almost-affine effective income taxation in the countries in our study, we restrict ourselves here to affine policies.
} 
of all pairs $(a, c)$, where $a \in[0,1], g$ is the observed value of government revenues from income taxation per capita, net of transfer payments, and $c$ is given by (2.4). That is to say, we shall restrict our search (for the equal opportunity tax policy) to those policies which are revenue neutral, in the sense of holding constant the government revenue used for non-transfer-payment purposes.

We number types in ascending order of circumstantial advantage. Let $\mathbf{F}^{1}$ be the probability measure of wages in the most disadvantaged type, and let $A=\int w^{1+\eta}$ $\mathrm{d} \mathbf{F}^{1}(w)$. Then the average post-fisc income of the worst-off type at policy $a$ is:

$$
(1-a)\left(\frac{1-a}{\hat{\alpha}}\right)^{\eta} A+a\left(\frac{1-a}{\hat{\alpha}}\right)^{\eta} B-g
$$

Assuming that the post-fisc distributions of income do not cross, EOp requires us to maximize this expression over all feasible policies $a$ in $\Phi$. (As we said, we are holding $g$ constant.) Setting the derivative of this expression with respect to $a$ equal to zero and solving gives us the optimal tax policy:

$$
a^{\mathrm{EOp}}=\operatorname{Max}\left[1-\frac{\eta B}{(1+\eta)(B-A)}, 0\right]
$$

The intuition for this formula is as follows. Typically, $B$ will be significantly larger than $A$. In this case, $a^{\mathrm{EOp}}>0$. But if the distribution of wages of the worst-off type is not very different from the distribution of wages of the whole society, then $B-A$ will be small, and, according to (2.5), $a^{\mathrm{EO}}=0$. This means that there should be no redistributive taxation to equalize opportunities for income: any taxation would be counter-productive, given the deadweight losses incurred, since there is so little inequality of opportunity, pre-fisc. The EOp policy, in this case, is simply to tax every citizen the lumpsum $g .^{10}$

We shall compare the actual tax regime to the EOp regime as follows. We first choose a 'benchmark' policy in $\Phi$, namely the policy with $c=0$. This is the tax policy that would tax all incomes at a proportional rate $a^{\text {bench }}$ that would just suffice to raise government expenditures of $g$ per capita, and make no inter-citizen transfers. We let $V_{1}$ equal the average post-fisc income of the worst-off type at this policy. We let $V_{2}$ be the average post-fisc income of the worst-off type at the observed policy, and we let $V_{3}$ be the average post-fisc income of the worst-off type at the policy $a^{\text {EOp }}$. We now define

$$
\nu=\frac{V_{2}-V_{1}}{V_{3}-V_{1}}
$$

If $\nu=0$, then the observed policy is the benchmark policy, and if $\nu=1$, then the observed policy is the EOp policy. Thus, $\nu$ can be thought of as the extent to

\footnotetext{
${ }^{10}$ For simplicity of exposition, we ignore the fact that persons of very low income cannot pay the lump sum tax.
} 
which the observed policy achieves EOp, relative to the benchmark of 'no transfers'. Finally, it should be mentioned that the observed policy might overtax in the sense that it redistributes more than EOp requires. In this case, we shall simply write ' $\nu=$ OT, for 'overtaxation'.

We next inquire into the 'efficiency cost' of achieving equality of opportunity — but here 'efficiency' is used in the traditional sense of 'the size of the pie'. We can ask: how much would national income shrink (expand) if we were to pass from the present policy to the EOp policy? We define the efficiency, $\varepsilon$, of EOp as follows:

$$
\varepsilon=\frac{\int x\left(w ; \varphi^{E O p}\right) \mathrm{d} \mathbf{F}(w)}{\int x(w ; \hat{\varphi}) \mathrm{d} \mathbf{F}(w)},
$$

which is just the ratio of average pre-fisc incomes at the EOp and observed policies. If $\varepsilon<1$, then there is some cost, in loss of average incomes, in moving from the observed policy to the EOp policy, and if $\varepsilon>1$, then there is an increase in average incomes in that move.

From the last two paragraphs, the reader must note that 'the efficiency of present policy with regard to the EOp objective' and 'the efficiency cost of implementing EOp' are two quite different ideas - although they are related: if the first number $(\nu)$ is close to one then the second number $(\varepsilon)$ will also be close to one.

We next explain how we compute the distribution of wages for a country, for it was the wage distributions that we used in the deduction of the optimal tax, above. We shall observe incomes, pre-fisc and post-fisc, not 'wages'. We shall assume that pre-fisc income is produced by an individual who maximizes utility, and has a certain wage-earning capacity. We shall assume a given value for the elasticity $\eta$. (Indeed, our method will be the perform the whole calculation for three values of $\eta$, for each country. It is clear that the smaller is $\eta$, the smaller is the income loss due to taxation, and hence the larger will be the marginal tax rate, $a^{\mathrm{EOp}}$, in the EOp regime.) We calibrate $\alpha$ by assuming that the individual with median income works one unit of time. By hypothesis, at the observed policy $\hat{a}$, incomes must be related to wages by the relation:

$$
x(w ; \hat{a}, \hat{c})=\left(\frac{1-\hat{a}}{\hat{\alpha}}\right)^{\eta} w^{1+\eta}
$$

Thus, having the observed distribution of pre-tax income, we can invert Eq. (2.6) and find the distribution of wages, what we have denoted F. In like manner, we compute the distribution of wages in the most disadvantaged type, $\mathbf{F}^{1}$. These are the only distributions that we need.

We see, according to this procedure, that individuals who have a high income will be assigned a high wage. Thus, if one individual has a higher wage than 
another in his type, this is viewed as the consequence of his having exerted higher effort. In micro detail, the higher wage may be due to having more education, to working more hours per year than our utility function predicts, to having been a more valuable employee, or to having good luck. All of these causes may be legitimately viewed as forms of higher effort, except the last one.

A final conceptual remark is in order. Some will object that the ethics of our equal-opportunity formulation are marred, because we (the ethical observers) take income as the opportunity equalisandum, but the citizens in the societies we study, by hypothesis, maximize something else, their 'utility', as measured by the function $u$. Non-paternalism would seem to require that we, as well, take that utility as the opportunity equalisandum. We do not wish to make a principle of our choice: we could as well have carried out the exercise with 'utility' in the place of 'income', and our results would probably differ little from what we report below. Our choice of income is dictated by the following consideration. Formula (1.1) requires, for its coherence, that the outcome, measured by $v$, be at least cardinally measurable and unit comparable (CUC), and level comparable. (That $v$ be at least CUC is required because we are adding up utilities across persons, and that it be level comparable is required because we are taking minima across types.) The conjunction of these two requirements is that $v$ be at least what is called absolutely measurable and comparable (AC). (See Roemer, 1996, Chapter 1, for a discussion of measurablility and comparability of utility.) Income is surely AC across persons, but it is much harder to argue that we know utility functions for individuals that are AC. In contrast, our use of utility functions in this article only requires that they be representations of individuals' ordinal preferences over income and leisure. Had we chosen to study 'equality of opportunity for welfare', our venture might have been more philosophically pure, but it would open the Pandora's box of the interpersonal comparability of welfare.

\section{The data sets}

Our empirical analysis uses household survey and administrative micro-data from 11 different countries: Belgium, France, Germany (East and West), Denmark, Great Britain, Italy, The Netherlands, Norway, Spain, Sweden, and the USA. These data sources allow us to calculate the pre-fisc and post-fisc income of individuals, and also contain information about personal and household characteristics and family background (used to classify types).

Tables 1 and 2 describe the main characteristics of the data sets. Samples refer to individuals who are male heads of household 25-40 years old (30-40 years old for Denmark, 25-50 years old for Germany). The average age ranges from 32.3 to 37.6. Most samples contain between 1000 and 2000 observations.

Income is expressed in per annum terms in thousands of units of local currency. 
Table 1

Surveys used, and summary statistics for pre- and post-fisc income distributions

\begin{tabular}{|c|c|c|c|c|c|c|c|c|c|c|}
\hline \multirow[t]{2}{*}{ Country } & \multicolumn{4}{|c|}{ Survey } & \multicolumn{4}{|c|}{$\begin{array}{l}\text { Pre-fisc income - ST definition } \\
\text { Mean (Coefficient of Variation), by type }\end{array}$} & \multicolumn{2}{|c|}{$\begin{array}{l}\text { Tax regression } \\
r^{2} \text { statistics }^{\mathrm{b}}\end{array}$} \\
\hline & Year & $\begin{array}{l}\text { Survey } \\
\text { name }^{\mathrm{a}}\end{array}$ & $\begin{array}{l}\text { Sample } \\
\text { size }\end{array}$ & Taxes & ED1 & ED2 & ED3 & Total & Linear & Ouadratic \\
\hline Belgium & 1992 & PSBH & 1043 & Simulated & $\begin{array}{c}659.64 \\
(0.56)\end{array}$ & $\begin{array}{r}802.92 \\
(0.51)\end{array}$ & $\begin{array}{r}913.18 \\
(0.61)\end{array}$ & $\begin{array}{r}745.18 \\
(0.57)\end{array}$ & 0.92 & 0.93 \\
\hline France & 1994 & BDF & 2763 & Partly simulated & $\begin{array}{r}125.315 \\
(0.59)\end{array}$ & $\begin{array}{r}148.043 \\
(0.66)\end{array}$ & $\begin{array}{r}174.975 \\
(0.70)\end{array}$ & $\begin{array}{r}145.284 \\
(0.68)\end{array}$ & 0.94 & 0.94 \\
\hline Germany, West & 1994 & GSOEP & 1117 & Simulated & $\begin{array}{c}44.169 \\
(0.57)\end{array}$ & $\begin{array}{c}50.971 \\
(0.77)\end{array}$ & $\begin{array}{c}51.074 \\
(0.59)\end{array}$ & $\begin{array}{c}45.744 \\
(0.61)\end{array}$ & 0.95 & 0.95 \\
\hline Germany, East & 1994 & GSOEP & 517 & Simulated & $\begin{array}{r}28.968 \\
(0.58)\end{array}$ & $\begin{array}{r}27.354 \\
(0.38)\end{array}$ & $\begin{array}{l}31.718 \\
(0.66)\end{array}$ & $\begin{array}{r}29.015 \\
(0.57)\end{array}$ & 0.90 & 0.91 \\
\hline Denmark & 1993 & IDA-ISR & 42387 & Observed & 209 & 230 & 253 & 216 & 0.77 & 0.79 \\
\hline Great Britain & 1991 & BHPS & 1051 & Simulated & $\begin{array}{r}227.43 \\
(0.53)\end{array}$ & $\begin{array}{r}253.80 \\
(0.68)\end{array}$ & $\begin{array}{r}318.76 \\
(0.78)\end{array}$ & $\begin{array}{r}288.79 \\
(0.77)\end{array}$ & 0.98 & 0.98 \\
\hline Italy & 1993 & SHIW & 1435 & Simulated & $\begin{array}{l}24.56 \\
(0.63)\end{array}$ & $\begin{array}{l}34.58 \\
(0.68)\end{array}$ & $\begin{array}{l}45.66 \\
(0.70)\end{array}$ & $\begin{array}{l}36.11 \\
(0.73)\end{array}$ & 0.97 & 0.98 \\
\hline The Netherlands & 1995 & AVO & 1758 & Simulated & $\begin{array}{l}61.2 \\
(0.78)\end{array}$ & $\begin{array}{l}70.9 \\
(0.61)\end{array}$ & $\begin{array}{l}73.7 \\
(0.60)\end{array}$ & $\begin{array}{l}69.0 \\
(0.65)\end{array}$ & 0.88 & 0.88 \\
\hline Norway & 1995 & SLL & 595 & Observed & $\begin{array}{r}231.50 \\
(0.48)\end{array}$ & $\begin{array}{r}248.90 \\
(0.68)\end{array}$ & $\begin{array}{r}254.90 \\
(0.70)\end{array}$ & $\begin{array}{r}243.10 \\
(0.62)\end{array}$ & 0.91 & 0.91 \\
\hline Spain & 1991 & $\mathrm{ECBC}$ & 1986 & Simulated & $\begin{array}{r}587.09 \\
(1.29)\end{array}$ & $\begin{array}{r}808.49 \\
(1.29)\end{array}$ & $\begin{array}{r}1182.24 \\
(1.59)\end{array}$ & $\begin{array}{r}716.06 \\
(1.41)\end{array}$ & 0.95 & 0.97 \\
\hline Sweden & 1991 & LNU & 825 & Observed & $\begin{array}{r}141.91 \\
(0.53)\end{array}$ & $\begin{array}{r}144.39 \\
(0.48)\end{array}$ & $\begin{array}{r}161.62 \\
(0.66)\end{array}$ & $\begin{array}{r}146.98 \\
(0.56)\end{array}$ & 0.73 & 0.73 \\
\hline USA & 1991 & PSID & 1140 & Simulated & $\begin{array}{l}26.62 \\
(0.51)\end{array}$ & $\begin{array}{l}30.89 \\
(0.44)\end{array}$ & $\begin{array}{l}38.66 \\
(0.66)\end{array}$ & $\begin{array}{l}31.99 \\
(0.59)\end{array}$ & 0.99 & 0.99 \\
\hline
\end{tabular}

Annual income in thousands of local currency (monthly income for Belgium, weekly for Britain). Individuals are male household heads 25-40 years old (30-40 years old for Denmark).

${ }^{a}$ PSBH, Panel Survey of Belgian Households; BDF, French Household Survey; GSOEP, German Socio-economic Panel; IDA-ISR, Danish integrated database for labour market research with income registers; BHPS, British Household Panel Survey; SHIW, Italian Survey of Household Income and Wealth; AVO, Dutch Facilities Use Survey; SLL, Norwegian Survey of Level of Living; ECBC, Spanish Survey on Class Structure, Social Biography, and Class Consciousness; LNU, Swedish Level of Living Survey; PSID, US Panel Study of Income Dynamics.

${ }^{\mathrm{b}}$ Tax regression $r^{2}$ statistics show the estimated $r^{2}$ from regressions of post-fisc income on pre-fisc income, using linear and quadratic specifications.

Two definitions of income are used. In the first specification, labeled ST-income ('standard' income), pre-fisc income is calculated as the individual's labor income, plus his household's capital income divided by the number of adults in the household. (For Belgium, calculations do not include the self-employed, or data on capital income.) Post-fisc ST-income is defined as pre-fisc income plus cash transfers from the government, minus income tax payments and social security 
Table 2

Descriptive statistics, by type

\begin{tabular}{|c|c|c|c|c|c|c|c|c|c|c|c|c|}
\hline \multirow[t]{2}{*}{ Country } & \multicolumn{3}{|c|}{$\begin{array}{l}\text { Age groups used to define ED } \\
\text { types }^{\mathrm{a}} \text { (Father's education, years) }\end{array}$} & \multicolumn{4}{|c|}{$\begin{array}{l}\text { Average years of education of } \\
\text { individuals }{ }^{\mathrm{b}}\end{array}$} & \multicolumn{4}{|c|}{ Average age of individuals ${ }^{b}$} & \multirow{2}{*}{$\begin{array}{l}\text { Mean } \\
\text { household } \\
\text { size }\end{array}$} \\
\hline & ED1 & ED2 & ED3 & ED1 & ED2 & ED3 & Total & ED1 & ED2 & ED3 & Total & \\
\hline Belgium & $<10$ & $10-12$ & $>12$ & 10.4 & 12.4 & 13.9 & 11.6 & 34.0 & 33.0 & 32.5 & 33.3 & 3.30 \\
\hline France & $\mathrm{OC} 1$ & $\mathrm{OC} 2$ & OC3 & 9.4 & 10.7 & 11.9 & 10.5 & 33.6 & 33.0 & 33.3 & 33.3 & 3.28 \\
\hline Germany, West & $<10$ & $10-13$ & $>13$ & 11.6 & 13.2 & 15.1 & 12.2 & 37.9 & 37.0 & 36.3 & 37.6 & 2.96 \\
\hline Germany, East & $<10$ & $10-13$ & $>13$ & 12.3 & 13.3 & 14.6 & 12.6 & 38.2 & 35.1 & 36.3 & 37.6 & 3.23 \\
\hline Denmark & $<8$ & $8-13$ & $>13$ & 11.6 & 12.4 & 13.7 & 12.0 & 34.6 & 34.1 & 33.9 & 34.2 & 2.76 \\
\hline Great Britain & $\mathrm{OC} 1$ & $\mathrm{OC} 2$ & OC3 & 12.1 & 12.3 & 13.9 & 13.2 & 33.2 & 33.0 & 32.5 & 32.8 & 3.06 \\
\hline Italy & $<5$ & $5-7$ & $>7$ & 8.0 & 9.8 & 12.7 & 10.4 & 34.7 & 34.3 & 33.8 & 34.2 & 3.35 \\
\hline The Netherlands & $<6$ & $6-9$ & $>9$ & 10.3 & 11.5 & 13.6 & 11.7 & 34.2 & 32.6 & 31.9 & 32.9 & \\
\hline Norway & $<9$ & $9-11$ & $>11$ & 11.2 & 12.0 & 13.1 & 12.0 & 33.3 & 32.0 & 32.0 & 32.5 & 3.03 \\
\hline Spain & $<4$ & $4-8$ & $>8$ & 8.1 & 10.1 & 13.0 & 9.5 & 32.9 & 32.6 & 31.4 & 32.6 & 3.76 \\
\hline Sweden & $<8$ & $8-11$ & $>11$ & 11.5 & 12.5 & 14.4 & 12.4 & 32.8 & 31.7 & 31.7 & 32.3 & 2.60 \\
\hline USA & $<12$ & 12 & $>12$ & 12.6 & 13.4 & 14.7 & 13.5 & 33.8 & 33.8 & 33.2 & 33.6 & 3.17 \\
\hline
\end{tabular}

a 'EDi' is the $i$ th type for the 'parental education' typology. 'OCi' is the $i$ th type for the typology based on father's occupation.

${ }^{\mathrm{b}}$ Individuals are male household heads 25-40 years old (30-40 years old for Denmark).

contributions. ${ }^{11}$ For the Nordic countries in our study we have data on actual tax payments made by sample respondents. In all other cases, taxes were simulated using information about the country's laws concerning income tax and social security contribution liabilities and the incomes and household characteristics available in the survey.

We do as well a series of calculations based on a second income definition (EQ-income). In this case, we define pre-fisc income as the household total of labor and capital income, which is then adjusted to take account of differences in household 'needs'. The equivalence scale is the square root of household size (see Atkinson et al., 1995). Large household sizes are generally due to older children's living at home, and the prevalence of this practice differs across countries in our sample. Post-fisc EQ-income is calculated by adding cash transfers to, and subtracting income taxes and social security contributions from, household pre-fisc income, with the resulting total then being divided by the square root of household size. Table 2 shows that the mean household size in our samples ranges from 2.6 in Sweden to 3.8 in Spain.

In most countries, income tax payments of households are simulated. The simulation formulae may over-estimate the taxes paid by high income groups, who can practice sophisticated tax avoidance (not captured by the simpler characterizations of the tax schedule that the simulations had to use). If this factor is important,

\footnotetext{
${ }^{11}$ Cash transfers are included in the definition of income liable for taxation according to the laws of most of the countries we consider.
} 
the extent to which actual tax systems achieve equalization of opportunities for income acquisition is probably less than what our estimates below indicate, based, as they are, on the simulations. Mitigating against this effect is the fact that survey under-response of capital income is more important among higher income groups: this would lead to an under-estimation of taxation for these groups.

In order to obtain estimates of the actual mapping of pre-fisc into post-fisc income, we regressed individuals' post-fisc income on their pre-fisc income. Table 1 shows the $r^{2}$ statistics of the linear and quadratic regressions for each country, using the ST definition of income. Although laws defining tax and social security contribution liabilities apparently characterize rather complex relationships between pre-tax and post-tax incomes, it turns out that affineness is a very good description of the effective tax regime data for all the countries that we examine. Affineness is thus a suitable assumption for our purposes.

Table 3 shows the differences in the level and composition of tax revenues in the countries of the sample. Our measure of post-fisc income is obtained by subtracting from the pre-tax income the personal income tax and the social security contributions of workers (which includes both the contributions of employees and, except for Belgium, self-employed). To the extent that some (or all) of the other contributions are borne by workers, the redistributive impact of the tax system may be underestimated. This could be particularly important in countries like Sweden, Italy or Spain where more than $70 \%$ of the contributions are paid by employers.

Our next step consists in partitioning the samples into types based on circumstances. We define two different typologies of individuals: one characterizes

Table 3

Taxes in OECD countries, 1990

\begin{tabular}{|c|c|c|c|c|c|c|c|c|c|}
\hline \multirow[t]{2}{*}{ Country } & \multicolumn{3}{|c|}{$\begin{array}{l}\text { Income and profit taxes } \\
\text { (as \% of GDP) }\end{array}$} & \multicolumn{5}{|l|}{$\begin{array}{l}\text { Other taxes } \\
\text { (as \% of GDP) }\end{array}$} & \multirow[t]{2}{*}{$\begin{array}{l}\text { Total } \times 100 \\
\div \text { GDP }\end{array}$} \\
\hline & Personal & Other & Total & $\begin{array}{l}\text { Social security, } \\
\text { Worker }\end{array}$ & $\begin{array}{l}\text { Social security, } \\
\text { Other }\end{array}$ & Property & Consumption & Other & \\
\hline Belgium & 14.0 & 2.4 & 16.4 & 5.4 & 9.3 & 1.2 & 11.6 & - & 44.0 \\
\hline France & 5.2 & 2.3 & 7.5 & 7.4 & 11.9 & 2.3 & 12.4 & 2.2 & 43.7 \\
\hline Germany, West & 10.1 & 1.8 & 11.9 & 6.7 & 7.0 & 1.2 & 9.8 & 0.0 & 36.7 \\
\hline Germany, East & NA & $\mathrm{NA}$ & NA & NA & NA & NA & NA & NA & $\mathrm{NA}$ \\
\hline Denmark & 25.6 & 2.8 & 28.4 & 1.2 & 0.3 & 2.1 & 16.4 & 0.4 & 48.7 \\
\hline Great Britain & 10.5 & 3.8 & 14.3 & 2.6 & 3.6 & 2.9 & 11.6 & 1.5 & 36.6 \\
\hline Italy & 10.3 & 4.0 & 14.3 & 3.7 & 9.2 & 0.9 & 11.0 & 0.1 & 39.2 \\
\hline The Netherlands & 11.0 & 3.4 & 14.4 & 13.3 & 3.3 & 1.6 & 11.8 & 0.1 & 44.6 \\
\hline Norway & 10.9 & 3.8 & 14.7 & 4.0 & 6.9 & 1.2 & 14.9 & - & 41.8 \\
\hline Spain & 7.4 & 3.1 & 10.5 & 3.4 & 8.7 & 1.9 & 9.7 & - & 34.2 \\
\hline Sweden & 21.4 & 1.8 & 23.2 & 0.6 & 14.5 & 2.0 & 13.9 & 1.5 & 55.6 \\
\hline USA & 10.1 & 2.0 & 12.1 & 3.3 & 3.6 & 3.1 & 4.6 & - & 26.7 \\
\hline
\end{tabular}

Source: Revenue Statistics (OECD). 
the individual by his parents' level of education, and the second characterizes the individual by his parents' occupation. In the first case we identify three educational levels (ED1 to ED3) that create three sizeable groups. In the second case we define three (sometimes four) occupational groups: farmers, unskilled manual workers, skilled manual, and professionals and self-employed. Furthermore, for some countries we shall further refine these typologies into a typology with six types, by partitioning each of the above-described types into two elements, characterized by whether the individual received an above or below average score on an IQ test taken during youth.

Tables 1 and 2 present descriptive statistics associated with the first typology, based on parental education, for all countries except for France and Great Britain where we use the occupational typology. For each survey we partition the sample into three types (ED1 to ED3) according to the level of education of the more highly educated parent. Table 1 shows the mean pre-fisc income of these groups. According to these basic statistics, the mean income of the three types is very different in Spain and Italy. At the other extreme, we find Norway and Sweden with quite similar pre-fisc income levels across types. Intra-type inequality (judging by the coefficient of variation) appears to be larger for type ED3 than for the other types, in all countries except Germany-west and The Netherlands ${ }^{12}$.

Table 2 also shows that individuals in ED3 have, on average, between 2 and 5 more years of education than those in ED1. The largest differences appear in Italy and Spain, and may be partly responsible for the large degree of inter-type income inequality (see below) observed in these countries. Note, as well, that ED3 is younger than ED1 in all countries, and so the higher income of the former group cannot be due to more labor market experience. Because of this age discrepancy, our sample also underestimates the degree of unequal opportunities among the three ED types (that is, were our sample to contain ED3 individuals of the same age as ED1 individuals, observed income differences would be greater). ${ }^{13}$

\section{Results}

Tables 4-7 present the results of four calculations, where type is defined as ED (parental education) or OC (parental occupation), and where income is defined in either the ST or EQ manner. These four tables present the results for the assumption $\eta=0.06$. We also ran the calculations for $\eta=0.03$ and 0.09 , but do not report all those results. We concentrate our discussion on Table 4.

From the $a^{\mathrm{obs}}$ and $a^{\mathrm{EOp}}$ columns of Table 4, we see that the EOp marginal tax

\footnotetext{
${ }^{12}$ The coefficient of variation is very sensitive to outliers. If three observations are removed from the Dutch data set, then the coefficient of variation is largest for the ED3 type there, as well.

${ }^{13}$ Along the same lines, the permanent income of ED3 individuals may be substantially higher than that of ED1 individuals, a fact that is not captured in our analysis.
} 
Table 4

EOp policy, $\eta=0.06$, ED typology, standard (ST) definition of income

\begin{tabular}{|c|c|c|c|c|c|c|c|c|}
\hline Country & $a^{\mathrm{obs}}$ & $c^{\mathrm{obs}}$ & $a^{\mathrm{EOp}}$ & $c^{\mathrm{EOp}}$ & $a^{\text {bench }}$ & $\rho$ & $\nu$ & $\varepsilon$ \\
\hline Belgium & 0.531 & 148.9 & 0.535 & 158 & 0.316 & 0.72 & 0.9996 & 0.9995 \\
\hline Germany, West & 0.364 & 5539.6 & 0 & -17477 & 0.225 & 0.85 & OT & 1.028 \\
\hline Germany, East & 0.330 & 4887.7 & SVC & SVC & 0.139 & 0.82 & NA & NA \\
\hline Denmark & 0.440 & 41021 & 0 & -53989 & 0.251 & 0.83 & OT & 1.035 \\
\hline Italy & 0.232 & 2.688 & 0.819 & 21.3 & 0.156 & 0.53 & 0.160 & 0.920 \\
\hline The Netherlands & 0.533 & 10410 & 0.474 & 18736 & 0.253 & 0.83 & OT & 1.007 \\
\hline Norway & 0.393 & 45526 & 0 & -63170 & 0.258 & 0.74 & OT & 1.030 \\
\hline Spain & 0.376 & 172.8 & 0.605 & 663.9 & 0.080 & 0.51 & 0.748 & 0.973 \\
\hline Sweden & 0.524 & 46886 & 0 & -30207 & 0.203 & 0.88 & OT & 1.046 \\
\hline USA & 0.243 & 2036 & 0.647 & 13578 & 0.182 & 0.69 & 0.200 & 0.955 \\
\hline
\end{tabular}

$a^{\text {obs }}$ and $c^{\text {obs }}$ are the regression coefficients of the best-fitting line $y^{\text {post }}=(1-a) y^{\text {pre }}+c$. Thus, $a$ is the marginal tax rate. $a^{\mathrm{EO}}$ and $c^{\mathrm{EOp}}$ give the optimal affine tax scheme, according to EOp. $a^{\text {bench }}$ is the proportional tax rate which would just raise non-transfer-payment government revenue. Thus, the larger $a^{\text {bench }}$, the larger is the 'value of public goods' per capita. The difference $a^{\text {obs }}-a^{\text {bench }}$ is the fraction of income taxation directed to redistribution.

$\rho$ is a measure of pre-tax equality of opportunity; it is the ratio of mean $y^{\text {pre }}$ in the lowest type to mean $y^{\text {pre }}$ in the highest type.

$\nu$ is the extent to which actual policy achieves the EOp policy, from the 'benchmark'. 'OT' means there is overtaxation: actual policy is more redistributive than EOp policy would be. 'SVC' means there is 'severe crossing' of the income CDF of the most disadvantaged type with other CDFs, and so our method of computing the EOp policy is inapplicable.

$1-\varepsilon$ is the fraction of shrinkage in the national wage bill at the EOp policy, in comparison to the observed policy. With overtaxation, $\varepsilon>1$, and the national wage bill would increase under EOp.

rate is smaller than the observed marginal rate in Denmark, Norway, Sweden, The Netherlands, and Germany, West; in Germany, East, there is no unambiguous inequality of opportunity, pre-fisc, in the sense that the income distribution

Table 5

EOp policy, ED typology, EQ definition of income, $\eta=0.06$

\begin{tabular}{llclcllll}
\hline Country & $a^{\text {obs }}$ & \multicolumn{1}{l}{$c^{\text {obs }}$} & $a^{\text {EOp }}$ & \multicolumn{1}{l}{$c^{\text {EOp }}$} & $a^{\text {bench }}$ & $\rho$ & $\nu$ & $\varepsilon$ \\
\hline Belgium & 0.555 & 178.9 & 0.661 & 238 & 0.260 & 0.69 & 0.90 & 0.984 \\
Germany, West & 0.404 & 6247.8 & 0.116 & -6424 & 0.215 & 0.84 & OT & 1.024 \\
Germany, East & 0.365 & 6113.9 & 0.227 & 4513 & 0.126 & 0.69 & OT & 1.012 \\
Denmark & 0.369 & 36435 & 0 & -36000 & 0.182 & 0.81 & OT & 1.028 \\
Italy & 0.247 & 2.428 & 0.829 & 16.43 & 0.154 & 0.46 & 0.186 & 0.915 \\
The Netherlands & 0.545 & 8660 & 0.510 & 18699 & 0.256 & 0.75 & OT & 1.004 \\
Norway & 0.389 & 47454 & 0.215 & 2773 & 0.202 & 0.76 & OT & 1.015 \\
Spain & 0.400 & 341.6 & 0.556 & 823.7 & 0.100 & 0.50 & 0.84 & 0.982 \\
Sweden & 0.569 & 48367 & 0 & -24258 & 0.185 & 0.87 & OT & 1.052 \\
USA & NA & NA & NA & NA & NA & NA & NA & NA \\
\hline
\end{tabular}

When $a^{\mathrm{EOp}}$ is 0 , there is no redistributive taxation at EOp; everyone contributes an equal lump-sum to fund public goods. Hence when this occurs, $c^{\mathrm{EO}}<0$. This occurs when pre-fisc inequality among types is so small that redistributive taxation is not worthwhile, because of deadweight loss. 
Table 6

EOp policy, OC typology, ST definition of income; $\eta=0.06$

\begin{tabular}{llclcllll}
\hline Country & $a^{\text {obs }}$ & \multicolumn{1}{c}{$c^{\text {obs }}$} & $a^{\text {EOp }}$ & $c^{\text {EOp }}$ & $a^{\text {bench }}$ & $\rho$ & $\nu$ & $\varepsilon$ \\
\hline Belgium & 0.531 & 148.9 & 0.278 & -71.4 & 0.324 & 0.92 & OT & 1.03 \\
Germany, West & 0.361 & 5470 & 0.031 & -14831 & 0.220 & 0.863 & OT & 1.025 \\
Germany, East & 0.328 & 4825 & 0 & -6891 & 0.156 & 0.833 & OT & 1.024 \\
Denmark & 0.440 & 41022 & 0 & -53989 & 0.250 & 0.90 & OT & 1.035 \\
France & 0.313 & 19.48 & 0.578 & 55.18 & 0.177 & 0.72 & 0.503 & 0.971 \\
Italy & 0.232 & 2.688 & 0.645 & 16.63 & 0.156 & 0.73 & 0.237 & 0.955 \\
Norway & 0.393 & 45526 & 0 & -63170 & 0.259 & 0.77 & OT & 1.030 \\
Spain & 0.376 & 172.8 & 0.758 & 768.8 & 0.090 & 0.42 & 0.568 & 0.945 \\
Great Britain & 0.364 & 38.43 & 0.709 & 171.5 & 0.070 & 0.72 & 0.615 & 0.954 \\
USA & 0.243 & 2036 & 0.663 & 14001 & 0.182 & 0.70 & 0.191 & 0.952 \\
\hline
\end{tabular}

For Germany, East, the worst-off type is ambiguous; the pre-tax CDFs cross.

functions of the supposedly most disadvantaged and middle types, cross severely ${ }^{14}$. This fact corresponds to the notation, in the $\nu$ column, that these five countries are classified as 'overtaxing': they tax more than equality of opportunity, with respect to the ED definition of circumstance, requires. It is particularly notable that four of these five countries (excepting The Netherlands) have an EOp tax rate of zero. This means that, at the EOp optimum, government spending would be financed by equal lump sum taxation of all citizens. There is, with our utility function, no deadweight loss with lump sum taxation. The way to interpret this result is that the pre-fisc inequality between types in these countries is so small that, even with a (fairly small) labor-supply elasticity of $\eta=0.06$, any proportional income taxation would produce a deadweight loss more than counteracting the benefit of increased opportunity equalization.

Belgium is essentially taxing at the EOp optimum ${ }^{15}$ : its efficiency $\nu$ is hardly

Table 7

EOp policy; OC typology, EQ definition of income; $\eta=0.06$

\begin{tabular}{llclcllll}
\hline Country & $a^{\text {obs }}$ & \multicolumn{1}{l}{$c^{\text {obs }}$} & $a^{\text {EOp }}$ & \multicolumn{1}{c}{$c^{\text {EOp }}$} & $a^{\text {bench }}$ & $\rho$ & $\nu$ & $\varepsilon$ \\
\hline Belgium & 0.555 & 178.9 & 0.397 & 84.7 & 0.257 & 0.89 & OT & 1.018 \\
Germany, West & 0.405 & 6543 & 0.410 & 11158 & 0.223 & 0.837 & 0.999 & 0.9995 \\
Germany, East & 0.357 & 5842 & 0 & -5706 & 0.141 & 0.816 & OT & 1.027 \\
Denmark & 0.369 & 36435 & 0 & -36000 & 0.182 & 0.90 & OT & 1.028 \\
France & 0.349 & 23.08 & 0.654 & 57.64 & 0.161 & 0.68 & 0.543 & 0.962 \\
Italy & 0.247 & 2.428 & 0.741 & 14.69 & 0.153 & 0.67 & 0.228 & 0.938 \\
Norway & 0.389 & 47454 & 0 & -46785 & 0.203 & 0.82 & OT & 1.030 \\
Spain & 0.400 & 341.6 & 0.639 & 931.1 & 0.110 & 0.41 & 0.731 & 0.970 \\
Great Britain & 0.384 & 41.99 & 0.743 & 118 & 0.216 & 0.70 & 0.447 & 0.949 \\
\hline
\end{tabular}

\footnotetext{
${ }^{14}$ This is an effect of the aims of the former German Democratic Republic to equalize opportunities.

${ }^{15}$ But recall that the self-employed are not in the Belgian sample.
} 
below unity. Of the four remaining countries, Italy clearly has the least effective taxation, from the EOp viewpoint: its efficiency is 0.16 . The US is not far behind, with an efficiency of 0.200. Notably, although the observed tax rate in Spain is not terribly high (0.376), its EOp efficiency is quite good, at 0.748. This is due to the large degree of pre-fisc inequality in Spain. Fig. $2 \mathrm{a}-\mathrm{c}$ present the pre-fisc income distribution functions of the three types in the US, Spain, and Denmark, respectively, from which this claim is evident.

It is worth recalling that our exercise defines the feasible set of policies as affine taxation which are revenue neutral, with respect to the funding of non-transferpayment government spending $(g)$. Of course, much of that spending will also have an equal-opportunity effect, such as monies spent on education and health, but we have not attempted to estimate that effect. We can, however, observe the relative magnitudes of this spending across countries by considering the 'benchmark' situation, in which there are no cash transfers in each country, just spending on $g$-type services. Refer to the $a^{\text {bench }}$ column of the table. (Recall that $a^{\text {bench }}$ is the fraction at which aggregate pre-fisc income would have to be taxed just to fund the ' $g$ ' component of government expenditures, leaving no revenue for transfer payments to citizens. It is the marginal tax rate at which $c=0$ (see Eq. 2.4).) Belgium, The Netherlands, Denmark, Norway, Sweden, and West Germany all spend more than $20 \%$ of national income on government services.

The $\rho$ column of these tables reports a measure of pre-fisc inequality. In Italy and Spain, the average pre-fisc income of the least advantaged type is barely more than half of the average pre-fisc income of the most advantaged type. In Sweden, Denmark, The Netherlands, and the two Germanies, this ratio is over $80 \%$. An interesting question would be to partition the causes of this high pre-fisc ratio in the northern Europe among the following three: population homogeneity, role of education, and role of the 'solidaristic wage' policy (that is, small wage differentials).

The last column of the table reports the ratio of the size of the income pie at the EOp tax regime to its size at the observed regime. It is of course the case that countries that are 'overtaxing' have $\varepsilon>1$. In Italy, we estimate that the cost of enacting an EOp tax policy would be about $8 \%$ of national income; in the US, slightly less than 5\%; in Great Britain (see Table 6), also slightly less than $5 \%$.

Table 6 reports the results for the occupational typology, and the standard definition of income. Here, we have data on France and Great Britain, both of which perform rather poorly with regard to equality of opportunity, compared to northern Europe. Italy remains the outlier in continental Europe, followed on the bottom by the US.

Table 8 reports the results of three calculations with different typologies. The first row takes the population sample as the immigrant population in Germany, and partitions members according to the OC.ST typology. There is no unambiguous pre-fisc inequality of opportunity; we suggest that this may illustrate the importance of family connections in producing inequality of opportunity - connections 

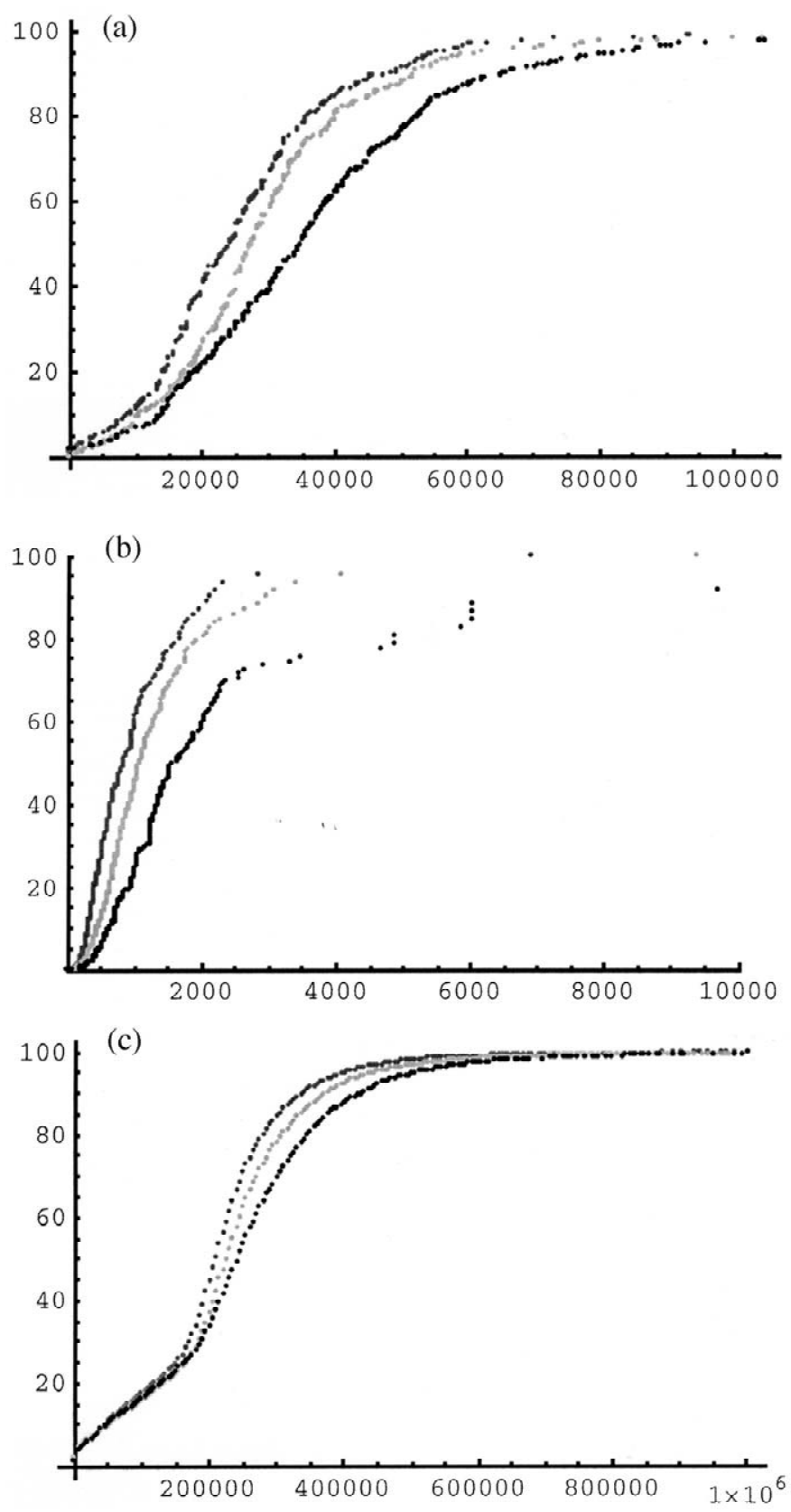

Fig. 2. (a) Empirical distribution functions of pre-fisc income, three ED types, ST definition of income, US. (b) Empirical distribution functions of pre-fisc income, three ED types, Spain. (c) Empirical distribution functions of pre-fisc income, ED types, Denmark. 
Table 8

Miscellaneous; $\eta=0.06$

\begin{tabular}{lllllllll}
\hline Country & $a^{\text {obs }}$ & $c^{\text {obs }}$ & $a^{\text {EOp }}$ & $c^{\text {EOp }}$ & $a^{\text {bench }}$ & $\rho$ & $\nu$ & $\varepsilon$ \\
\hline GI.OC.ST & Sv Cr & & & & & & \\
GBRC.EQ & Sv Cr & & & & & & & \\
NDAL.ST & 0.533 & 10410 & 0.384 & 10719 & 0.270 & 0.75 & OT & 1.017 \\
\hline
\end{tabular}

Notes: GI.OC.ST takes the universe as immigrants in Germany, and performs the OC.ST calculation. GBRC.EQ is a typology in Great Britain, according to race (RC); the types are white or non-white. NDAL.ST is a typology in The Netherlands where a person is either native born or foreign born (alien). This calculation uses the EQ definition of income.

which, for immigrants, have in large part been severed. The second row uses the British sample, and types individuals as white or non-white. Again, there is no unambiguous pre-fisc inequality of opportunity. We attribute this to the fact that Asians and Blacks are not distinguished in this typology. (Thus, Asians have incomes that are not lower than whites, and so the distribution functions of the 'white' and 'non-white' types cross.) The obvious move would be to do so, but there are too few observations in some of the type cells with a further refinement of type to do this. The last row of the table partitions The Netherlands sample into two types, defined by whether the individual was born in The Netherlands or abroad. Interestingly, The Netherlands overtaxes with respect to eliminating inequality of opportunity between these types.

Table 9 reports various calculations for the elasticity $\eta=0.03$. With this assumption, there is very little deadweight loss to taxation, so EOp will generally require higher taxation than when $\eta=0.06$. We observe, remarkably, that east Germany, Denmark, Norway and Sweden continue to be classified as overtaxing. Italy and the US now have efficiency ratings of just above 0.12.

How should one interpret the result that the northern European countries are all taxing either at or above the EOp optimum? We suggest two alternative interpretations. The first is that, indeed, these countries are moving beyond an equal-opportunity ethic towards an 'equal outcome' ethic.

We believe this is too hasty a conclusion. Recall that our method implicitly treats all intra-type income differences not ascribable to the explicit circumstances we name as due to 'effort.' In the results thus far reported, we have characterized the individual's circumstances by one characteristic, the education or occupation of his parent. This single characteristic captures much of what inequality of opportunity consists in. But it surely does not capture the influence of all factors beyond a person's control on his income earning capacity.

The second interpretation is that other characteristics that we have ignored contribute as well to inequality of opportunity. Prominent among these is the natural ability of individuals.

In four countries - the US, Denmark, Sweden, and The Netherlands - we 
Table 9

Various EOp policies, $\eta=0.03$

\begin{tabular}{|c|c|c|c|c|c|c|c|c|}
\hline Country & $a^{\text {obs }}$ & $c^{\text {obs }}$ & $a^{\mathrm{EOp}}$ & $c^{\mathrm{EOp}}$ & $a^{\text {bench }}$ & $\rho$ & $\nu$ & $\varepsilon$ \\
\hline $\begin{array}{l}\text { Germany, West } \\
\text { OC.ST }\end{array}$ & 0.361 & 5470 & 0.451 & 17265 & 0.223 & 0.86 & 0.82 & 0.995 \\
\hline $\begin{array}{l}\text { Germany, East } \\
\text { OC.ST }\end{array}$ & 0.328 & 4825 & 0 & -6891 & 0.159 & 0.83 & OT & 1.012 \\
\hline $\begin{array}{l}\text { Denmark } \\
\text { ED.ST }\end{array}$ & 0.440 & 41022 & 0 & -53989 & 0.251 & 0.83 & OT & 1.018 \\
\hline $\begin{array}{l}\text { Spain } \\
\text { ED.ST }\end{array}$ & 0.376 & 173 & 0.748 & 819 & 0.087 & 0.51 & 0.577 & 0.973 \\
\hline Belgium ED.ST & 0.531 & 148.9 & 0.758 & 313 & 0.320 & 0.72 & 0.647 & 0.980 \\
\hline France OC.ST & 0.313 & 19.47 & 0.782 & 83.22 & 0.179 & 0.72 & 0.306 & 0.971 \\
\hline $\begin{array}{l}\text { The Netherlands } \\
\text { ED.ST }\end{array}$ & 0.533 & 10410 & 0.745 & 42468 & 0.277 & 0.83 & 0.717 & 0.982 \\
\hline $\begin{array}{l}\text { Norway } \\
\text { ED.ST }\end{array}$ & 0.393 & 45526 & 0.255 & -1157 & 0.260 & 0.74 & OT & 1.006 \\
\hline $\begin{array}{l}\text { Sweden } \\
\text { ED.ST }\end{array}$ & 0.524 & 46886 & 0 & -30207 & 0.207 & 0.88 & OT & 1.023 \\
\hline $\begin{array}{l}\text { Britain } \\
\text { OC.ST }\end{array}$ & 0.364 & 38.43 & 0.850 & 210.2 & 0.071 & 0.72 & 0.471 & 0.958 \\
\hline $\begin{array}{l}\text { Italy } \\
\text { ED.ST }\end{array}$ & 0.232 & 2.688 & 0.902 & 25.03 & 0.157 & 0.53 & 0.126 & 0.940 \\
\hline $\begin{array}{l}\text { USA } \\
\text { ED.ST }\end{array}$ & 0.243 & 2036 & 0.815 & 18541 & 0.184 & 0.69 & 0.127 & 0.959 \\
\hline
\end{tabular}

have secondary data sets which contain data on IQ tests taken during youth. ${ }^{16}$ (The tests were administered at age 14 in Denmark, at age 13 in Sweden, at age 12 in The Netherlands, and in the interval 15-23 years in the US.) Regardless whether the grade on these tests reflects genetic endowment or family culture (nature or nurture), it is a measure of the person's circumstances. And even if there is a 'hard work' component to what IQ measures, since these tests were taken in childhood, arguably before the 'age of consent' at which we should view individuals responsible for their acts, we should as well consider it a measure of circumstances. Our next exercise refines the ED typology, in these four countries, into a six-type classification, where each ED type is partitioned into two elements, corresponding to 'above' and 'below' average IQ.

Because the IQ data in each of these countries were not in our main sample, we simulated these six types, in the main sample, as follows. In each country our secondary data set contains the IQ data, information on parental education, and information on the respondent's income as a young adult. We partitioned the

\footnotetext{
${ }^{16}$ We thank Joop Hartog for providing us with the Brabant data set for The Netherlands. See Hartog (1992) for his work based on this data set. We thank Erik Jorgen Hansen for providing us with the data for Denmark from the SFI study 'Ungdomsforlobsundersogelsen'; see Hansen (1995) for his work using this data set. We thank Carl-Gunnar Janson for access to his data for Sweden.
} 
Table 10

The matrix $p(i, t)$ for The Netherlands

\begin{tabular}{llll}
\hline $\begin{array}{l}\text { Fifth of the income } \\
\text { distribution }\end{array}$ & $\mathrm{ED}=1$ & $\mathrm{ED}=2$ & $\mathrm{ED}=3$ \\
\hline Poorest & 0.33 & 0.52 & 0.60 \\
Second poorest & 0.31 & 0.44 & 0.76 \\
Middle & 0.35 & 0.44 & 0.81 \\
Second richest & 0.57 & 0.61 & 0.86 \\
Richest & 0.62 & 0.68 & 0.76 \\
\hline
\end{tabular}

samples in the secondary data sets into the three ED types, and then calculated the numbers $p(i, t)$, the fraction of individuals in the $i$ th income quintile group (fifth of the income distribution) of the $t$ th ED type who scored above average on the IQ test. (Thus, $t$ ranges from one to three, and $i$ from one to five.) We then returned to the primary data set, partitioned each of the three ED types into five income quintile groups, and then randomly assigned each individual in the $(i, t)$ cell an IQ of 'above average' with probability $p(i, t)$, and an IQ of 'below average' with a probability of $1-p(i, t)$. We then partitioned the primary data set into six types, accordingly. The panels of Tables $10-13$ present the matrix $p$ for the four

Table 11

The matrix $p(i, t)$ for the US

\begin{tabular}{llll}
\hline $\begin{array}{l}\text { Fifth of the income } \\
\text { distribution }\end{array}$ & $\mathrm{ED}=1$ & $\mathrm{ED}=2$ & $\mathrm{ED}=3$ \\
\hline Poorest & 0.15 & 0.31 & 0.55 \\
Second poorest & 0.14 & 0.29 & 0.62 \\
Middle & 0.16 & 0.46 & 0.72 \\
Second richest & 0.20 & 0.51 & 0.78 \\
Richest & 0.43 & 0.74 & 0.88 \\
\hline
\end{tabular}

Table 12

The matrix $p(i, t)$ for Denmark

\begin{tabular}{llll}
\hline $\begin{array}{l}\text { Tenth of the income } \\
\text { distribution }\end{array}$ & $\mathrm{ED}=1$ & $\mathrm{ED}=2$ & $\mathrm{ED}=3$ \\
\hline Poorest & 0.34 & 0.34 & 0.44 \\
Second & 0.36 & 0.38 & 0.48 \\
Third & 0.38 & 0.41 & 0.52 \\
Fourth & 0.41 & 0.43 & 0.55 \\
Fifth & 0.43 & 0.45 & 0.59 \\
Sixth & 0.46 & 0.47 & 0.63 \\
Seventh & 0.48 & 0.49 & 0.66 \\
Eighth & 0.50 & 0.51 & 0.70 \\
Ninth & 0.53 & 0.53 & 0.74 \\
Richest & 0.55 & 0.55 & 0.77 \\
\hline
\end{tabular}


Table 13

The matrix $p(i, t)$ for Sweden

\begin{tabular}{llll}
\hline $\begin{array}{l}\text { Fifth of the income } \\
\text { distribution }\end{array}$ & $\mathrm{ED}=1$ & $\mathrm{ED}=2$ & $\mathrm{ED}=3$ \\
\hline Poorest & 0.36 & 0.42 & 0.68 \\
Second poorest & 0.30 & 0.41 & 0.69 \\
Middle & 0.28 & 0.41 & 0.51 \\
Second richest & 0.52 & 0.43 & 0.75 \\
Richest & 0.47 & 0.71 & 0.82 \\
\hline
\end{tabular}

Table 14

Contrast of EOp policies, with and without IQ as a circumstance, $\eta=0.06$

\begin{tabular}{lllll}
\hline Country & $a^{\text {EOp }}$ & $\rho$ & $\nu$ & $\varepsilon$ \\
\hline US, three types ED.ST & 0.647 & 0.69 & 0.200 & 0.955 \\
US, six types (with IQ) & 0.723 & 0.61 & 0.165 & 0.941 \\
DK, three types ED.ST & 0 & 0.828 & OT & 1.035 \\
DK, six types (with IQ) & 0 & 0.710 & OT & 1.035 \\
SW, three types ED.ST & 0 & 0.88 & OT & 1.046 \\
SW, six types (with IQ) & 0.257 & 0.78 & OT & 1.027 \\
ND, three types ED.ST & 0.470 & 0.830 & OT & 1.007 \\
ND, six types (with IQ) & 0.700 & 0.69 & 0.767 & 0.959 \\
\hline
\end{tabular}

countries. We see that above-average IQ is generally associated with higher income, and with more advantaged type.

Table 14 reports the results of the EOp calculation, for these four countries, for the six-type typology, and compares it to the corresponding calculations for the ED.ST typology. We see that, when IQ is accounted for, The Netherlands is no longer overtaxing. To equalize opportunities would now require a marginal tax rate of $70 \%$ in The Netherlands. Denmark and Sweden continue to overtax, although the EOp tax rate in Sweden is no longer zero, but 25\%. Most remarkably, even accounting for IQ, the EOp taxation in Denmark should be strictly lump sum. Note that this is not explained simply by the degree of pre-fisc inequality. Denmark has somewhat more pre-fisc inequality than Sweden: the below-averageIQ, low-parental-education type in Denmark has an average pre-fisc income of $71 \%$ of the average pre-fisc income of the above-average-high-parental-education type, whereas the corresponding figure is $78 \%$ in Sweden. The EOp calculation uses facts about the entire distribution of incomes of the various types, which are only imperfectly reflected in this single statistic.

\section{Conclusion}

We have asked to what extent income taxation, in 11 countries, equalizes opportunities among young men for the acquisition of income. The novelty of the 
equal-opportunity approach is its partitioning of income differentials into two categories, the first due to differential circumstances beyond the control of individuals, the second due to individual variation in voluntary effort. The equal-opportunity ideal uses the instrument at hand (here, income taxation) to annihilate differentials of the first kind but not of the second kind. The corresponding ethic is that differences in outcomes due to circumstance should, from a moral viewpoint, be compensable at the bar of justice, while differences due to effort should not be.

Our method proceeds by singling out certain obvious circumstances, and attributing all remaining variation in incomes to differential effort. When we choose the level of parental education as the single circumstance, we find that in northern Europe, income-taxation regimes are either optimal from the EOp viewpoint, or go too far — in the Nordic countries, there is so little pre-fisc inequality of incomes across types that only lump sum taxation is justified from the EOp viewpoint. We then introduce native ability as a second circumstance, and find that, remarkably, Sweden and Denmark continue to tax more than equality of opportunity requires.

Were we to introduce finer variations in the delineation of circumstance - for instance, by partitioning IQ into four intervals, instead of two - we might well find that Sweden and Denmark do not continue to overtax from the EOp viewpoint. Nevertheless, it seems fair to say that these countries perform very well with regard to the EOp ethic. Further work would be required to explain the low degree of pre-fisc inequality among types in these countries, that accounts for their good performance with respect to the EOp criterion.

We must emphasize, however, that our choice of the policy space has also painted a rosier picture than, in truth, should be painted. We have restricted our instrument to a unidimensional space of tax policies. If we had allowed, for instance, the taxation of different types according to different marginal tax rates, then all of our countries would have performed more poorly, with respect to the achievement of equal opportunity, than they have here. We did not work on that policy space, however, because we wished our exercise to be viewed as realistic from a political viewpoint. So our more circumscribed statement is: given the restriction of policies to ones of affine income taxation in which all citizens face the same tax policy, the northern European countries do very well in regard to equalizing opportunities for income acquisition.

We remark on an efficiency issue that we have not thus far discussed: what is the best instrument for equalizing opportunities for income acquisition? Another possibly effective instrument would be education. We could, in principle, calculate how increasing expenditures on education would effect the type distributions of income, and then evaluate whether educational finance was a more efficient way of equalizing opportunities for income acquisition than redistributive taxation. While such an investigation is clearly beyond the scope of the present paper, it should be remarked that the educational finance instrument would not necessarily come out ahead. For example, despite efforts of many countries to reduce educational 
barriers to members of disadvantaged types, those barriers remain effectively quite high (see Shavit and Blossfeld, 1993). In fact, sociological researchers of stratification have suggested that a low degree of income inequality fosters equalization of educational and occupational opportunities, rather than the other way around. (For a thorough discussion, see Erikson and Goldthorpe (1992), Jonsson et al. (1996).) Income taxation, blunt instrument though it may be for our purpose, may be one of the best available.

Indeed, the difficulty of increasing the proportion of members of disadvantaged types who pursue tertiary education is surely, to some unknown extent, due to their preferences, and not to what we might think of as hard barriers (like imperfect credit markets). We might rightly consider those preferences, even if they are in large part determined by circumstances, to be the responsibility of the individuals who hold them ${ }^{17}$, and if so, the lower incomes that follow from their lower educational levels would not be compensable at the bar of equal opportunity. For further discussion of this philosophical issue, the reader is referred to the last footnote, and to the appropriate references below.

\section{Acknowledgements}

We are grateful to the Fundacion Urrutia Elejalde and the Russell Sage Foundation for financing two meetings of the authors. Our thanks as well go to research assistants Marcus Grabka (Berlin), René Böheim (Essex), and Helene B. Lilleor (Copenhagen).

\section{References}

Arneson, R., 1989. Equality and equality of opportunity for welfare. Philosophical Studies 56, 77-93. Arneson, R., 1990. Liberalism, distributive subjectivism, and equal opportunity for welfare. Philosophy \& Public Affairs 19, 159-194.

Atkinson, A.B., Rainwater, L., Smeeding, T.M., 1995. Income distribution in OECD countries, Social Policy Studies No. 18, OECD, Paris.

Cohen, G.A., 1989. On the currency of egalitarian justice. Ethics 99, 906-944.

Dworkin, R., 1981a. What is equality? Part 1: Equality of welfare. Philosophy \& Public Affairs 10, 185-246.

Dworkin, R., 1981b. What is equality? Part 2: Equality of resources. Philosophy \& Public Affairs 10, $283-345$.

\footnotetext{
${ }^{17}$ Dworkin (1981b) considers preferences with which the individual identifies, whether or not they were induced by circumstances, to be within the ambit of personal responsibility. Roemer (1998), however, does not, for preferences might have been adopted to make life manageable in an environment with bad circumstances (cognitive dissonance).
} 
Erikson, R., Goldthorpe, J.H., 1992. The Constant Flux. A Study of Class Mobility in Industrial Societies. Clarendon Press, Oxford.

Hansen, E.J., 1995. En generation bliver voksen - Den forst velfaerdsgeneraion. Copenhagen: Socialforskningsinstitutet, Rapport 95, 8.

Hartog, J., 1992. Capabilities, Allocation and Earnings. Kluwer Academic Publishers, Dordrecht.

Jonsson, J.O., Mills, D., Müller, W., 1996. A half century of increasing educational openness? Social class, gender and educational attainment in Sweden, Germany and Britain. In: Erikson, R., Jonsson, J.O. (Eds.), Can Education be Equalized ? The Swedish Case in Comparative Perspective. Westview Press, Boulder, CO.

Page, M., Roemer, J.E. The US fiscal system as an opportunity equalizing device. In: Hassett, K. (Ed.), The Role of Inequality in Tax Policy, American Enterprise Institute, Washington, DC, in press.

Roemer, J.E., 1993. A pragmatic theory of responsibility for the egalitarian planner. Philosophy \& Public Affairs 10, 146-166.

Roemer, J.E., 1996. Theories of Distributive Justice. Harvard University Press, Cambridge, MA.

Roemer, J.E., 1998. Equality of Opportunity. Harvard University Press, Cambridge, MA.

Shavit, Y., Blossfeld, H.-P. (Eds.), 1993. Persistent Inequality: Changing Educational Attainment in Thirteen Countries. Westview, Boulder, CO.

Van de Gaer, D., 1993. Equality of Opportunity and Investment in Human Capital. Faculty of Economics, Catholic University, Leuven. 